\title{
Generalist predators disrupt parasitoid aphid control by direct and coincidental intraguild predation
}

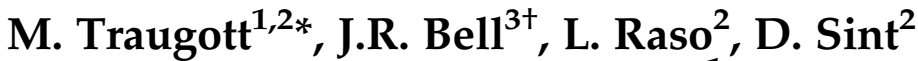 \\ and W.O.C. Symondson ${ }^{1}$ \\ ${ }^{1}$ Cardiff School of Biosciences, Biomedical Sciences Building, Cardiff \\ University, Museum Avenue, Cardiff CF10 3AX, UK: ${ }^{2}$ Mountain Agriculture \\ Research Unit, Institute of Ecology, University of Innsbruck, Technikerstrasse \\ 25, 6020 Innsbruck, Austria: ${ }^{3}$ Warwick HRI, University of Warwick, \\ Wellesbourne, Warwick, CV35 9EF, UK
}

\begin{abstract}
Generalist predators and parasitoids are considered to be important regulators of aphids. The former not only feed on these pests, but might also consume parasitoids at all stages of development. This direct or coincidental interference affects the natural control of aphids, the scale of which is largely unknown, and it has rarely been examined under natural conditions. Here, molecular diagnostics were used to track trophic interactions in an aphid-parasitoid-generalist predator community during the build-up of a cereal aphid population. We found that generalist predators, principally carabid and staphylinid beetles as well as linyphiid spiders, had strong trophic links to both parasitoids and aphids. Remarkably, more than $50 \%$ of the parasitoid DNA detected in predators stems from direct predation on adult parasitoids. The data also suggest that coincidental intraguild predation is common too. Generalist predators, hence, disrupt parasitoid aphid control, although the levels at which the predators feed on pests and parasitoids seem to vary significantly between predator taxa. Our results suggest that taxon-specific trophic interactions between natural enemies need to be considered to obtain a more complete understanding of the route to effective conservation biological control.
\end{abstract}

Keywords: agro-ecology, pest control, conservation biological control, intraguild predation, molecular prey detection

(Accepted 31 August 2011; First published online 10 October 2011)

\section{Introduction}

Aphids cause serious economic damage to cereal crops by transmitting viruses and, in outbreak years, by reducing yields

\footnotetext{
*Author for correspondence

Fax: + 435125076190

E-mail: Michael.Traugott@uibk.ac.at

tCurrent address: Plant and Invertebrate Ecology, Rothamsted Research, Harpenden, Hertfordshire, AL5 2JQ, UK
}

through direct feeding (van Emden \& Harrington, 2007). Fortunately, cereal aphids are attacked by a suite of natural enemies, including parasitoids and generalist predators (Chambers et al., 1986; Sunderland et al., 1997), both of which have been shown to be capable of reducing aphid population densities (Schmidt et al., 2003, 2004; Bell et al., 2008a; Macfadyen et al., 2009). This ecosystem service provides economic benefits to farmers. For example, the yield increase in spring barley attributable to generalist predators was found to be comparable with the yield increases from insecticide use (Östman et al., 2003). However, generalist predators do not only feed on the pest, but might also consume parasitoids, 
attenuating the overall pest suppression effect (Brodeur \& Rosenheim, 2000; Snyder \& Ives, 2001). Empirical evidence of this type of intraguild predation (IGP) stems either from studies employing observational approaches or cage experiments, where the assessment of feeding interactions is limited to particular taxa and where trophic connections are indirectly inferred. Although empirically established aphid-parasitoid food webs have been described previously (e.g. Müller et al., 1999; van Veen et al., 2008), polyphagous predators have yet to be integrated in these trophic networks to examine how they are connected to aphids and their parasitoids (but see Bell et al., 2010). This is mainly due to the practical difficulties inherent in identifying and quantifying predator-prey interactions from field data, especially for highly polyphagous species with less predictable diets (Symondson, 2002; van Veen et al., 2006). Their exclusion, however, considerably limits our understanding of the functioning of these natural enemy communities where generalist predators may regularly interfere with parasitoid aphid control. If generalist predators consume parasitoids and their hosts at random, this would have little effect on aphid-parasitoid interactions. However, random feeding by generalists is highly unlikely (Agusti et al., 2003; Harwood et al., 2007; Juen \& Traugott, 2007; Kuusk et al., 2008; King et al., 2010; Eitzinger \& Traugott, 2011). If, instead, generalist predators demonstrate prey choice, aphidparasitoid trophic interactions might be altered in ways that are not affected by internal aphid-parasitoid dynamics.

The aim of this study was to examine the trophic structuring within an aphid-parasitoid-generalist predator community using a molecular approach and to measure how frequently parasitoid and aphid prey are consumed by generalist predators such as carabid and staphylinid beetles or spiders. Our objectives were, therefore, three-fold: (i) to use PCR (polymerase chain reaction) to identify and measure the frequency of trophic interactions between aphids, parasitoids and predators, (ii) to examine how predation on aphids and parasitoids changes during aphid population growth, and (iii) to assess which predators are most likely to interfere with aphid control by parasitoids.

\section{Materials and methods}

\section{Experimental site and field sampling}

Field work was conducted in a 13-ha winter wheat field at the Warwick HRI experimental farm, Wellesbourne, Warwickshire, UK $\left(52^{\circ} 12.18^{\prime} \mathrm{N}, 1^{\circ} 36.00^{\prime} \mathrm{W}\right)$ within a larger experiment investigating the effects of compost addition on invertebrate predators and their prey. For a detailed description of how communities were sampled, see Bell et al. (2008a). Here, we focus on the aphid-parasitoid-predator food webs and combine the data from different compost treatments.

Ground-active predators were collected within quadrats $(0.5 \times 0.5 \mathrm{~m})$ using aspirators. Predators were taken from two quadrats within 16 experimental plots, totalling 32 quadrat samples per date. Quadrat sampling began on 24th May and ended on 3rd July 2005 (four collection dates), covering the period of the build-up of the aphid population. Predators were placed individually in $1.5-\mathrm{ml}$ reaction tubes, put on ice and frozen within $3 \mathrm{~h}$ at $-80^{\circ} \mathrm{C}$.

Aphid population densities were estimated over the 12-week period from 2nd May to 18th July. Total numbers of aphids were counted from four randomly selected wheat tillers per plot. Sitobion avenae (F.) represented the great majority of aphids, and other cereal aphid species, such as Rhopalosiphum padi (L.) and Metopolophium dirhodum (Walker), occurred at very low densities. All aphids collected were individually frozen at $-80^{\circ} \mathrm{C}$ and all $S$. avenae screened for parasitoid DNA to determine the rates of parasitism by each parasitoid species on each sampling date (Traugott et al., 2008).

In addition to the sampling program described above, arthropods occurring in the wheat field were also collected for cross-amplification testing with the aphid- and parasitoidspecific primers, using hand sampling, micro-aspirators or sweep nets. All non-predatory arthropods collected were freeze-killed on capture and stored in $80 \%$ ethanol for subsequent DNA extraction. Predators were handled differently to avoid the contaminating effects of parasitoid or aphid remains amongst their gut contents. These were starved for one week at room temperature to allow digestion and clearance of their guts, freeze-killed and then stored in $80 \%$ ethanol. Thereafter, these arthropod samples were DNA-extracted and used for cross-amplification testing, using the PCR assays described below.

\section{DNA extraction}

The DNA of parasitoids that emerged from aphids (Traugott et al., 2008), and other field-collected invertebrates used for cross-amplification testing, was extracted using a modified Chelex extraction protocol. The DNA of fieldcollected predators (whole animals) was extracted using DNeasy Blood \& Tissue Kit (Qiagen, Hilden, Germany) following the manufacturer's instructions; $200 \mu \mathrm{l}$ DNA extracts were stored at $-24^{\circ} \mathrm{C}$. Two extraction-negative controls were included in every batch of 48 samples and tested for DNA carry-over contamination using universal invertebrate primers as described in Traugott et al. (2008).

\section{Diagnostic multiplex and singleplex PCR}

A multiplex-PCR system was developed, allowing us to simultaneously screen predator gut contents for parasitoid and aphid DNA. Primer pairs, targeting S. avenae (S103/A103), the aphid parasitoids Ephedrus plagiator (Nees) (S115/A115) and four species of Aphidius (S108/A107), as well as the aphid hyperparasitoid Dendrocerus carpenteri (Curtis) (S120/A122), were designed from cytochrome c oxidase subunit I gene (COI) sequences (see table S1 in the supplementary material). Primers designed for use in the multiplex-PCR amplified short fragments, from $114 \mathrm{bp}$ to $231 \mathrm{bp}$, in order to increase prey DNA detection success (King et al., 2008). Optimisation of the PCR protocols included determination of optimum annealing temperatures by temperature-gradient PCR, testing different concentrations and combinations of primers in multiplex PCR and adjusting cycling conditions. Each $10 \mu \mathrm{l}$ multiplex-PCR reaction mix contained $2.5 \mu \mathrm{l}$ of extracted DNA, $1 \times$ multiplex-PCR master mix (Qiagen), $1.5 \mu$ l of PCR-water (Qiagen) and the primers at their respective concentration (table S1). The cycling conditions were $15 \mathrm{~min}$ at $95^{\circ} \mathrm{C}, 35$ cycles of $30 \mathrm{~s}$ at $94^{\circ} \mathrm{C}, 3 \mathrm{~min}$ at $62.5^{\circ} \mathrm{C}, 1 \mathrm{~min}$ at $72^{\circ} \mathrm{C}$ and final elongation for $10 \mathrm{~min}$ at $72^{\circ} \mathrm{C}$.

As the multiplex PCR included a group-specific primer pair, covering four Aphidius species detected in the fieldcollected aphids (Traugott et al., 2008), all aphids testing positive with this primer pair were retested in singleplex PCRs with species-specific primers to identify the respective Aphidius species (table S1). The six parasitoid species targeted 
in both singleplex- and multiplex-PCR assays accounted for $84.3 \%$ of all parasitoids detected by diagnostic PCR within the aphids sampled (Traugott et al., 2008), thus enabling us to measure predation on the most abundant parasitoid species. To confirm the results obtained by multiplex PCR, each sample testing positive for parasitoid or aphid DNA was retested in singleplex PCR using the appropriate primer pair. To ensure comparability between multiplex- and singleplex-PCR assays, the cycling conditions and reaction mix, as described above for multiplex PCR, were used, except that primer concentration was $1 \mu \mathrm{M}$. Within all PCRs, 1:10 diluted DNA of the target species was included as a positive control along with a minimum of four negative controls (DNA-free $\mathrm{H}_{2} \mathrm{O}$ ). All predator DNA extracts which tested negative for any of the prey species described above were tested for their ability to amplify in PCR as described in Traugott et al. (2008); $3.0 \%$ of DNA extracts did not amplify in these tests and were excluded from the analysis. All PCR assays were carried out in Eppendorf (Hamburg, Germany) Mastercyclers.

\section{PCR assay specificity and sensitivity}

Diagnostic analyses of both predation and parasitism require extensive cross-amplification tests to ensure their specificity (King et al., 2008). These tests were conducted for both multiplex- and singleplex-PCR assays and included $S$. avenae and the six aphid parasitoid species tested for, as well as five additional aphid species, four additional aphid and 15 non-aphid parasitoids, and other plant- and soil-dwelling invertebrates collected within the experimental field (see table S2). Before conducting the cross-amplification tests, DNA extracts from all taxa listed within tables S1 and S2 were tested for their ability to amplify in PCR using universal invertebrate primers (see above).

Primer sensitivity was determined for all primer pairs used in the singleplex and multiplex PCRs by testing dilutions of target DNA for amplification success (for the group-specific Aphidius primer pair DNA from Aphidius rhopalosiphi De Stefani was used). DNA concentration in the original extracts was determined using NanoDrop (NanoDrop Technologies, Wilmington, DE, USA), adjusted to $0.5 \mathrm{ng} \mu \mathrm{l}^{-1}$ and two-fold serially diluted. The serial diluted target DNA was then used as template in the multiplex and singleplex assays at concentrations of $62.5,31.3,15.6,7.8,3.9,1.9,0.98,0.49,0.24$, $0.12,0.061,0.031$ and 0.015 pg of parasitoid DNA per $\mu$ PCR.

PCR products were separated and detected using the QIAxcel System and QIAxcel DNA screening kit (Qiagen) with separation method AL320. Electropherograms were analysed and scored using BioCalculator Fast Analysis Software version 3.0 (Qiagen); all samples generating $>0.1$ fluorescent units (which is well above the cartridges' background fluorescence-induced error) were deemed to be positive. The fragment lengths of PCR products amplified from field-collected predators were determined by comparing them with PCR-fragments from the positive controls to reliably score amplified aphid and parasitoid DNA.

\section{Analysis}

Predator densities, as established from quadrat sampling, were compared between sampling dates within each predator group and for the pooled predator catches using KruskalWallis ANOVA and Mann-Whitney $U$ tests for pair-wise comparisons.
Parasitism rates for $S$. avenae are based on a previous analysis of aphid parasitism in the same winter wheat field (Traugott et al., 2008) using the data for the six parasitoid species targeted in the present paper. For prey detection rates in predators and parasitoid detection rates in S. avenae, $95 \%$ tilting confidence limits (CL), which adjust for bias and skewness in the bootstrap distribution and are asymmetrical (Hesterberg et al., 2003), were calculated by 9999 bootstrap resamples using S-PLUS 8.0 (Insightful Corporations, Seattle, WA, USA). To account for the significantly longer prey DNA detection times regularly found in spiders compared to carabid beetles (Sheppard et al., 2005; Traugott \& Symondson, 2008; Sint et al., 2011), prey detection rates were down-weighted in spiders to allow for more accurate comparison with prey detection in beetles. Down-weighting was based on the feeding experiments by Traugott \& Symondson (2008), in which aphid and parasitoid DNA detection success was found to be on average $48.2 \%$ (i.e. a factor of 2.1) higher in Erigone sp. compared to the carabid Demetrias atricapillus. This calculation is based on the differences in prey DNA detection between spiders and beetles observed for the time points $0,8,16,24$ and $32 \mathrm{~h}$ post-feeding for a $369 \mathrm{bp}$ aphid fragment and a $291 \mathrm{bp}$ parasitoid fragment. The difference in amplification success was calculated for each time point; and then the mean was calculated for the differences observed, leading to the $48.2 \%$ enhanced detection success in spiders as reported above. Hence, prey DNA detection in spiders was divided by 2.1 , and $95 \%$ tilting confidence limits were recalculated. Data from other feeding experiments where Tenuiphantes tenuis and Tachyporus sp. were fed with parasitized aphids (M. Traugott \& W.O.C. Symondson, unpublished data) suggest a very similar relationship.

IGP on parasitoids can either be direct, when predators capture and eat adult parasitoids, or coincidental, when parasitized aphids are eaten (Polis et al., 1989). Unfortunately, current DNA-based methodology does not allow us to differentiate between these two scenarios: predators which test positive for host and parasitoid DNA could have eaten a parasitized host or the prey DNA might stem from separate host and parasitoid meals. We considered predators which tested positive for parasitoid DNA only to be a conservative proxy for direct IGP, as aphid DNA is usually detectable as well when parasitized and mummified aphids are eaten (Traugott \& Symondson, 2008; Traugott et al., 2008). To estimate predation on unparasitized aphids, predators which tested positive for aphid DNA only were included, providing a proxy for aphid mortality due to predation. For both, the estimation of direct IGP and predation on unparasitized aphids, all four sampling dates were pooled. Note, however, that the estimated predation rates on unparasitized aphids might be overestimated due to consumption of aphids containing very early instar parasitoids, which are hard to detect using PCR-based approaches (Traugott \& Symondson, 2008). On the other hand, predation on unparasitized aphids and on adult parasitoids might be underestimated due to predators which consumed aphids and parasitoids in separate meals, which corresponds in our analysis to the consumption of parasitized aphids.

\section{Results}

\section{The invertebrate predator community}

The invertebrate predators collected within the quadrats (1255 individuals from 61 taxa; for details of species see 

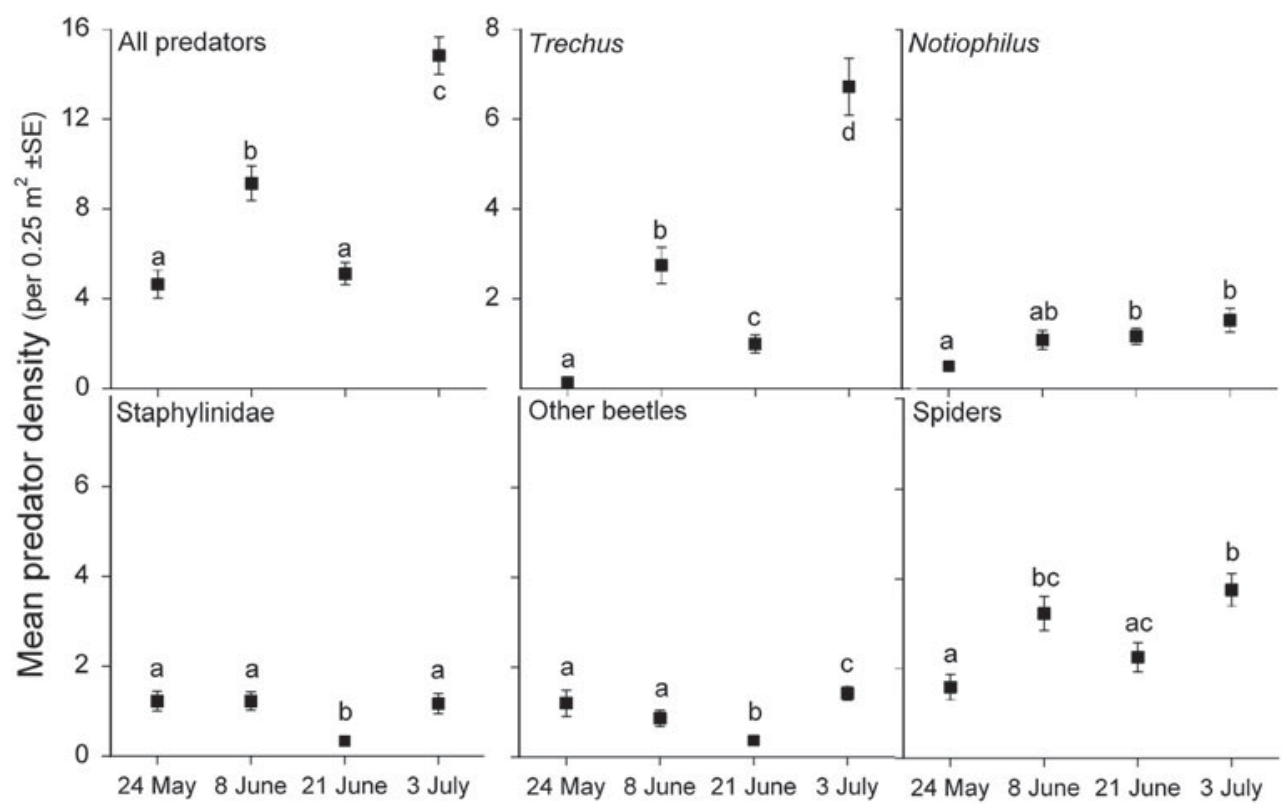

Fig. 1. Mean densities of arthropod predators sampled at four dates between 24 May and 3 July 2005 within a winter wheat field near Warwick, UK. At each date, mean arthropod densities were established from 36 quadrat $(0.5 \times 0.5 \mathrm{~m})$ samples. Different letters denote significant differences in predator densities at $P<0.05$.

table S3) were dominated by carabid beetles (53\%), spiders $(30 \%)$ and staphylinid beetles (12\%). Mean predator densities were similar on 24 May and 21 June ( $\sim 5$ individuals $0.25 \mathrm{~m}^{-2}$ ), whereas they doubled and tripled on 8 June and 3 July, respectively (fig. 1). Among the carabids, Trechus quadristriatus Schrank and Notiophilus biguttatus (F.) were most abundant and accounted for $59 \%$ and $24 \%$ of all ground beetles caught, respectively. Of the spiders caught, 95\% belonged to the Linyphiidae. Apart from unidentified juveniles (45\%), three species dominated within the linyphiids: Erigone atra (Blackwall) (17\%), Tenuiphantes tenuis (Blackwall) (14\%) and Bathyphantes gracilis (Blackwall) (10\%). Tachyporus hypnorum (F.) (29\%) was the most frequently collected staphylinid beetle. As most of the beetle and spider species were found only in low numbers, too few individuals were available for a meaningful predator-specific dietary analysis. Hence, the predators were amalgamated into five groups based on their abundance and functional attributes (Bell et al., 2008b): (i) T. quadristriatus, (ii) N. biguttatus, (iii) Coccinellidae, Cantharidae and other Carabidae (subsequently referred to as 'other beetles'), (iv) Staphylinidae and (v) spiders. Within each group, the magnitude of the average rank densities changed significantly between the sampling dates, with most pronounced differences in T. quadristriatus (fig. 1).

\section{PCR specificity and sensitivity}

Both the singleplex- and multiplex-PCR assays proved to be highly specific as no cross-amplification was found when the non-target species were tested. The sensitivities of the different primers used within the multiplex PCR differed only marginally (see appendix S1 in the supplementary material).

\section{Predation on aphids}

Numbers of $S$. avenae increased monotonically with sampling date and peaked in July at a mean density of 25.9
( $\pm 5.2 \mathrm{SE})$ aphids per four wheat tillers (fig. 2a). Although no aphids were detected on the wheat plants sampled on 24 May, $28.0 \%$ of all predators tested positive for DNA of S. avenae (fig. 2a, note that detection rates in spiders were downweighted), showing that the predators were preying on aphids even at low densities during their establishment phase. Aphid detection rates peaked on 21 June, when $33.3 \%$ of predators tested positive (fig. 2a). Overall, the highest proportion of predators testing positive for $S$. avenae was found in $N$. biguttatus $(64.0 \%)$, whereas less positives were obtained in other beetles $(50.4 \%)$ and staphylinids (38.0\%). Compared to $N$. biguttatus, a significant smaller proportion of spiders (18.9\%, down-weighted) and T. quadristriatus (5.8\%) contained DNA of $S$. avenae (table 1). Although there were significant differences in aphid prey detection rates between sampling dates in other beetles and spiders, this was not the case for staphylinids, T. quadristriatus and N. biguttatus (fig. 2a).

To estimate the average predation on unparasitized $S$. avenae over the whole season, only predators which tested positive for aphid DNA were considered, excluding those that also contained parasitoid DNA. This reduced S. avenae detection rates by approximately $30 \%$ in spiders and T. quadristriatus, as well as by approximately $10 \%$ in the other three predator groups. Of all predators where solely aphid DNA was detected, N. biguttatus, other beetles, spiders, rove beetles and T. quadristriatus accounted for 32.4\%, $23.6 \%$, $20.1 \%, 18.1 \%$ and $5.8 \%$, respectively.

\section{Predation on parasitoids}

Almost all parasitoid species targeted by the molecular assay were found to be consumed by the five predator groups when the data from the four sampling dates were pooled (table 2). Exceptions were T. quadristriatus, in which no A. ervi DNA was found, staphylinids (no D. carpenteri) and other beetles (no A. picipes). 


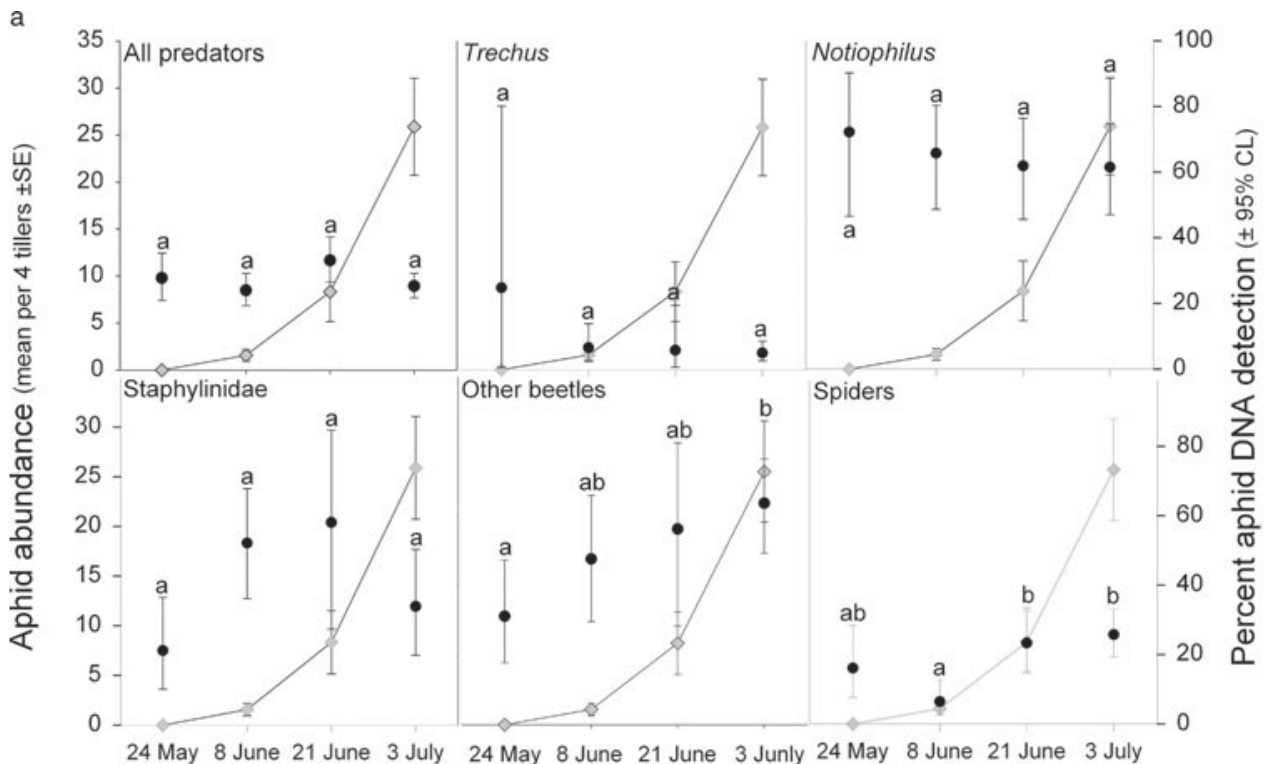

b
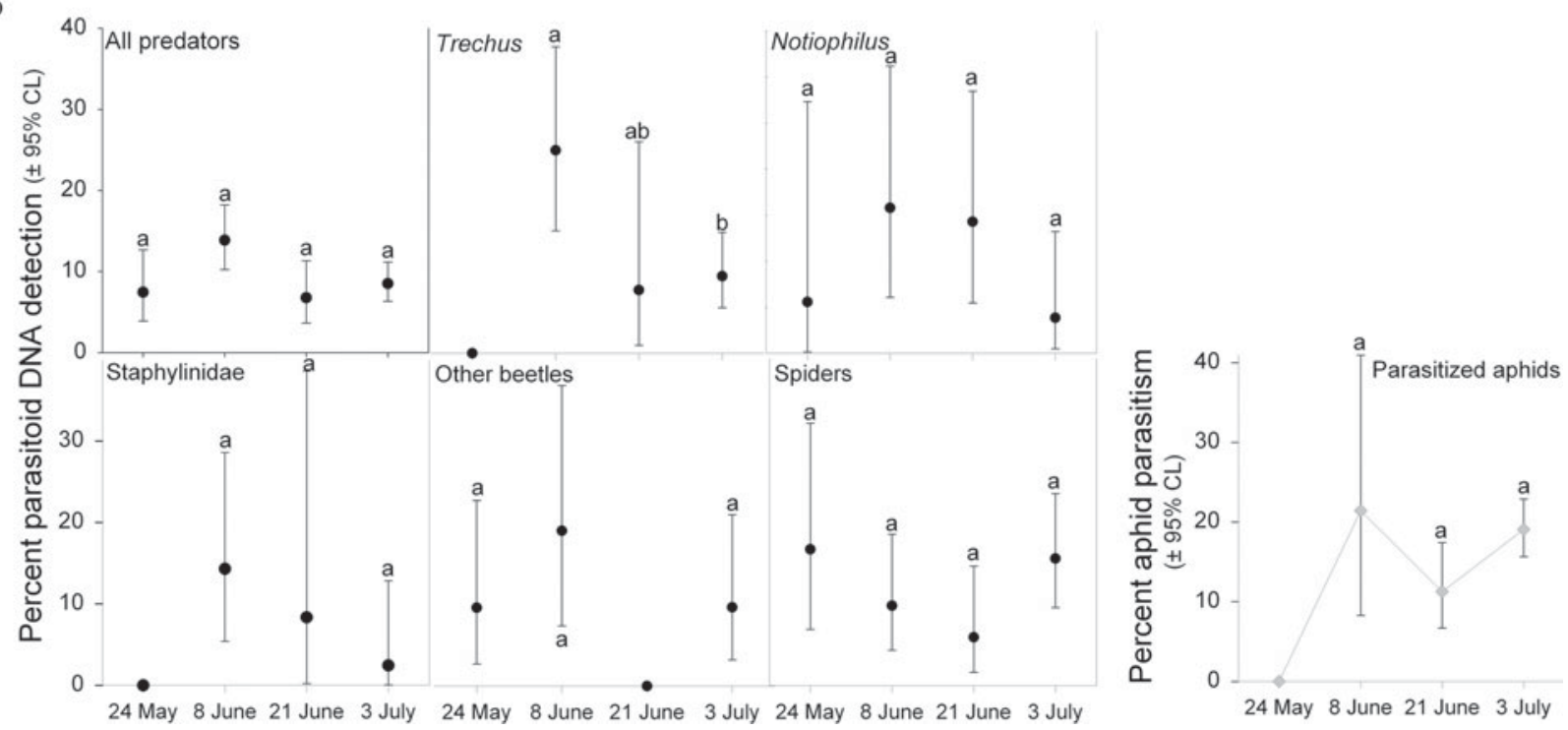

Fig. 2. (a) Aphid numbers (Sitobion avenae; 18 replicate samples per date) $(\diamond)$ and aphid DNA detection rates (\%) (•) and (b) aphid parasitism rates $(\%)(\diamond)$ and parasitoid DNA detection rates $(\%)(\bullet)$ in arthropod predators sampled at four dates between 24 May and 3 July 2005 within a winter wheat field near Warwick, UK. Prey DNA detection rates in spiders were down-weighted to allow for better comparison with beetle predators. Different letters denote non-overlapping confidence limits in DNA detection rates.

Parasitism rates by the six parasitoid species, detected using diagnostic PCR, ranged from $11.3 \%$ to $21.4 \%$ between June and July (fig. 2b). Although no parasitized aphids were found in the wheat samples taken on 24 May, 5.6\%, 9.8\% and $12.5 \%$ of $N$. biguttatus, other beetles (mostly carabids) and spiders (detection rates down-weighted), respectively, tested positive for parasitoid DNA (fig. 2b). Overall, no significant differences in parasitoid DNA detection rates between the five predator taxa were found (table 1). The same was true for parasitoid detection over time, except for T. quadristriatus, where the proportion of parasitoid positive beetles was significantly higher on 8 June compared to 3 July (fig. 2b).
From all other beetles, spiders, T. quadristriatus, Staphylinidae and N. biguttatus assayed in the present study, $8.6 \%, 7.9 \%, 5.8 \%, 3.5 \%$ and $2.6 \%$, respectively, contained parasitoid DNA in the absence of aphid DNA. This indicates that, aside from N. biguttatus (26.0\%) and spiders (41.8\%), in all other predator taxa, more than $50 \%$ of the parasitoid DNA stems from direct predation on adult parasitoids (T. quadristriatus $86.9 \%$, Staphylinidae $60.3 \%$, other beetles $53.2 \%$ ). The rate of predators containing solely parasitoid DNA changed between sampling dates; it was $13.8 \%, 7.6 \%$, $8.7 \%$ and $2.6 \%$ for 24 May, 8 June, 21 June and 3 July, respectively. 
Table 1. Percentages of arthropod predators testing positive for DNA of Sitobion avenae (aphid DNA) and parasitoid DNA. Predators were collected between 24 May and 3 July 2005 in a winter wheat field near Warwick, UK. For spiders, downweighted detection rates are provided. Lower (lCL) and upper (uCL) 95\% tilting confidence limit; different letters denote nonoverlapping confidence limit between taxa listed within the same column.

\begin{tabular}{lllr}
\hline \multicolumn{1}{c}{ Predator } & $\begin{array}{c}\text { \% aphid } \\
\text { DNA detection } \\
(\text { lCL, uCL })\end{array}$ & $\begin{array}{c}\text { \% parasitoid } \\
\text { DNA detection } \\
(\text { lCL, uCL })\end{array}$ \\
\hline (a) $\quad$ N. biguttatus & $64.0(55.7,71.7) \mathbf{a}$ & $10.0(5.7,15.9) \mathbf{a}$ \\
& Other beetles & $50.4(41.7,59.0) \mathbf{a c}$ & $10.9(6.3,17.4) \mathbf{a}$ \\
& Spiders & $18.9(15.3,23.0) \mathbf{b}$ & $9.1(6.5,12.3) \mathbf{a}$ \\
& Staphylinidae & $38.0(29.8,46.6) \mathbf{b c}$ & $5.8(2.5,11.2) \mathbf{a}$ \\
& T. quadristriatus & $5.8(3.6,8.6) \mathbf{d}$ & $9.9(7.0,13.4) \mathbf{a}$ \\
\hline
\end{tabular}

Among the parasitoid prey, E. plagiator was detected in higher proportions than other parasitoid species in spiders, $T$. quadristriatus and N. biguttatus (except D. carpenteri in $N$. biguttatus) (table 2). In spiders, rates of detection of the hyperparasitoid $D$. carpenteri were lower compared to those of the primary aphid parasitoids (except for A. ervi) (table 2).

More T. quadristriatus tested positive for parasitoids than for aphids, and spiders were characterized by a comparatively high parasitoid:aphid prey detection ratio (approx. 1:2) (table 1). Within the other predator groups, significantly more predators tested positive for S. avenae than for parasitoid prey (table 1). Moreover, $29.7 \%$ of T. quadristriatus and $31.8 \%$ of spiders which contained aphid DNA also tested positive for parasitoid prey. In the other three predator taxa/groups, however, these proportions ranged only between $9.6 \%$ and $12.5 \%$.

\section{Discussion}

The results show that generalist predators are tightly connected to both cereal aphids and their parasitoids, although the levels at which these prey were taken varied significantly among predator taxa. Aphid prey detection, in the absence of parasitoid DNA, ranged between $14 \%$ and $32 \%$ in N. biguttatus, other beetles, rove beetles and spiders. Taking these percentages as a proxy for aphid consumption, all four taxa seem to regularly feed on aphids. Trechus quadristriatus, albeit representing $31.3 \%$ of all predators caught, accounted for only $5.8 \%$ of predators in which solely aphid DNA could be detected. By contrast, this carabid species made up $49.2 \%$ of cases where only parasitoid DNA could be detected, followed by spiders, which made up for $27.1 \%$ of all parasitoid-positive predators. This conservative surrogate for predation on adult parasitoids indicates that these two predator taxa, in particular, might be capable of diminishing the adult parasitoid population. In both of these predator taxa, approximately one third of the beetles and spiders which contained aphid DNA also tested positive for parasitoid prey. In the other three predator taxa/groups, however, these proportions ranged only between $9.6 \%$ and $12.5 \%$, indicating that T. quadristriatus and spiders were not only the main predators of adult parasitoids but also responsible for the majority of coincidental intraguild predation on parasitoids.

During the four sampling dates, on average $17.2 \%$ of the collected aphids were parasitized and one would expect a similar percentage of parasitized prey within the predators if random feeding occurs. Therefore, our data suggest that, in both T. quadristriatus and spiders, either the consumption of parasitized aphids (i.e. coincidental IGP) was disproportionately high or many aphids and parasitoids were consumed in separate predation events and the DNA from both prey detected simultaneously in the guts of these predators. The latter would mean that direct predation on adult parasitoids in these groups is underestimated in our results. In both cases, T. quadristriatus and perhaps also spiders are likely to have reduced control of aphids by parasitoids, while simultaneously assisting aphid control through predation on these pests. The potential of generalist predators to disrupt parasitoid top-down control of aphids has already been shown experimentally by the carabid Pterostichus melanarius (Illiger) preying on A. ervi (Snyder \& Ives, 2001), although it was not known whether this was caused via feeding on mummified aphids or on other parasitoid developmental stages.

Interestingly, predators not only regularly consumed both parasitoids and their aphid hosts, but consumption of specific parasitoid species varied between predator species and over time. For example, predation rates by spiders, T. quadristriatus and $N$. biguttatus on the primary parasitoid E. plagiator were higher than on other primary parasitoids that showed similar or even higher rates of aphid parasitism (Traugott et al., 2008). Examining functional traits of both prey and predators may help to elucidate the mechanisms which drive these specific aphid-parasitoid-predator feeding interactions. For example, E. plagiator shows long developmental times and long adult lives compared to the other primary parasitoid species (Ruggle \& Holst, 1994). This may have increased its exposure to IGP compared to the other parasitoid species.

IGP is common in nature and can have a large influence on the trophic structuring of communities (Vance-Chalcraft et al., 2007). In the case of aphid-parasitoid communities, it has been hypothesized that IGP drives fluctuations in parasitoid populations and can substantially alter the effectiveness of parasitoids to control herbivores (Brodeur \& Rosenheim, 2000). The current data predict that direct IGP on aphid parasitoids is a common phenomenon in generalist predators, as more than $50 \%$ of the parasitoid DNA stems from direct predation on adult parasitoids. It is possible that some predators consumed parasitized $R$. padi and $M$. dirhodum and, as the aphid primers employed in our multiplex PCR were specific to $S$. avenae, only the DNA of the parasitoid would be detectable in these cases. However, as the densities of these two aphid species were much smaller compared to those of $S$. avenae (together $\sim 4 \%$ of all aphids collected), coincidental IGP events involving $R$. padi and $M$. dirhodum are unlikely to have significantly affected our estimate of direct predation on adult parasitoids. Interestingly, the predation pressure on parasitoid adults seemed to be higher at the first two sampling dates, when two-thirds of the parasitoidpositive predators contained exclusively parasitoid DNA, compared to 21 June and 3 July, when this rate dropped to onethird. The rate of predators testing positive exclusively for aphid DNA, however, was largely unaffected by sampling date, ranging between $75 \%$ and $87 \%$. These high rates of direct IGP on aphid parasitoids are surprising, contrasting with earlier studies which suggested that strong IGP on aphid parasitoids is unlikely to occur (Cardinale et al., 2003; Schmidt et al., 2003). The dearth of data on this type of IGP, however, is probably a reflection of the lack of suitable techniques in the past for detecting such links (but see Nakamura \& Nakamura, 1977), which can have important implications for both host 
Table 2. Percentages of arthropod predators testing positive for DNA of the five primary parasitoid species: Aphidius ervi (Ae), A. picipes (Ap), A. rhopalosiphi (Ar), A. uzbekistanicus (Au) and Ephedrus plagiator (Ep), as well as the hyperparasitoid Dendrocerus carpenteri (Dc). For spiders, down-weighted detection rates are provided. Predators were collected between 24 May and 3 July 2005 in a winter wheat field near Warwick, UK. Lower (lCL) and upper (uCL) 95\% tilting confidence limit; different letters denote non-overlapping confidence limit between taxa listed within the same line.

\begin{tabular}{|c|c|c|c|c|c|c|}
\hline \multirow[t]{2}{*}{ Predator group } & \multicolumn{6}{|c|}{$\%$ predators positive for $(\mathrm{lCL}, \mathrm{uCL})$} \\
\hline & $\mathrm{Ae}$ & $A p$ & $A r$ & $A u$ & $E p$ & $D c$ \\
\hline N. biguttatus & $\begin{array}{l}0.7 \\
(0.0,3.7) \mathbf{a}\end{array}$ & $\begin{array}{l}1.3 \\
(0.2,4.7) \mathbf{a}\end{array}$ & $\begin{array}{l}2.0 \\
(0.4,5.7) \text { ac }\end{array}$ & $\begin{array}{l}2.0 \\
(0.4,5.7) \text { ac }\end{array}$ & $\begin{array}{l}9.3 \\
(5.2,15.2) \mathbf{b c}\end{array}$ & $\begin{array}{l}3.3 \\
(1.1,7.6) \mathrm{ab}\end{array}$ \\
\hline Other beetles & $\begin{array}{l}0.7 \\
(0.0,4.0) \mathbf{a}\end{array}$ & $\begin{array}{l}0 \\
(0.0,0.0)\end{array}$ & $\begin{array}{l}2.2 \\
(0.5,6.3) \mathbf{a}\end{array}$ & $\begin{array}{l}1.5 \\
(0.2,5.2) \mathbf{a}\end{array}$ & $\begin{array}{l}6.6 \\
(3.1,12.1) \mathbf{a}\end{array}$ & $\begin{array}{l}0.7 \\
(0.0,4.0) \mathbf{a}\end{array}$ \\
\hline Spiders & $\begin{array}{l}0.2 \\
(0.0,1.3) \mathbf{a}\end{array}$ & $\begin{array}{l}2.2 \\
(1.0,4.0) \mathbf{a}\end{array}$ & $\begin{array}{l}2.9 \\
(1.5,5.0) \mathbf{a b}\end{array}$ & $\begin{array}{l}1.9 \\
(0.8,3.7) \mathbf{a}\end{array}$ & $\begin{array}{l}6.7 \\
(4.5,9.5) \mathbf{b}\end{array}$ & $\begin{array}{l}0.5 \\
(0.1,1.7) \mathbf{a}\end{array}$ \\
\hline T. quadristriatus & $\begin{array}{l}0 \\
(0.0,0.0)\end{array}$ & $\begin{array}{l}0.3 \\
(0.0,1.5) \mathbf{a}\end{array}$ & $\begin{array}{l}1.4 \\
(0.4,3.2) \mathbf{a}\end{array}$ & $\begin{array}{l}1.1 \\
(0.3,2.8) \mathbf{a}\end{array}$ & $\begin{array}{l}7.9 \\
(5.4,11.2) \mathbf{b}\end{array}$ & $\begin{array}{l}0.8 \\
(0.2,2.4) \mathbf{a}\end{array}$ \\
\hline
\end{tabular}

and parasitoid populations. Nevertheless, high rates of direct predation on parasitoid adults have been considered in earlier work as well; for example, Völkl \& Kraus (1996) calculated that $50 \%$ of female Pauesia unilachni (Hymenoptera: Braconidae), parasitoids of the grey pine aphid Schizolachnus pineti (Homoptera: Lachnidae), were expected to be caught by spiders during their first 24-h foraging period, which significantly affected parasitoid fitness and aphid control.

Our data suggest that coincidental IGP is common too, especially by spiders where parasitized aphids might constitute a significant proportion of their aphid prey $(\sim 30 \%)$. This highlights the need to consider coincidental IGP as a potentially significant driver, affecting both aphid and parasitoid population dynamics. As feeding experiments have shown that it is more difficult to detect the DNA of early stage parasitoids when they are consumed with their aphid hosts (Traugott \& Symondson, 2008), consumption of these early stage parasitoids, therefore, was probably underestimated. Moreover, behavioural aspects can increase predation rates on aphids as well. Generalist predators have been shown to aggregate at places where aphid densities are high, which leads to enhanced predation rates on parasitized aphids and in turn negatively affects parasitoid adult emergence (Chacon \& Heimpel, 2010).

The trophic data presented here indicate which predators show frequent trophic linking and, hence, are likely to affect the population dynamics of aphids and parasitoids. By examining these feeding interactions at several time points during aphid population development, temporal changes in the frequency of specific trophic links could be recorded. Manipulative experiments, in field cages, could now be used to determine how these trophic links, including their temporal dynamics, directly and indirectly affect the population dynamics of aphids and parasitoids. For example, the current data suggest that T. quadristriatus and linyphiid spiders act as important intraguild predators of both adult and immature aphid parasitoids during the build up of the aphid population. This IGP should negatively affect control of aphids by parasitoids, a hypothesis which can be tested in such experiments. Combining manipulative experimentation with molecular analysis of predation may also reveal why, in diverse predator communities, IGP does not necessarily disrupt herbivore control (e.g. Snyder et al., 2008).
No aphids were found during field sampling at the end of May, yet $28 \%$ of spiders and beetles collected at that first sampling date tested positive for aphid DNA. This indicates that the number of tillers inspected for aphids at this time was clearly too small to record the first aphids invading the field or that the aphids were largely being consumed by predators as quickly as they arrived. In previous studies, a similar phenomenon was found, with disproportionately high rates of aphid consumption by spiders before aphid numbers began to increase later on in the season (Harwood et al., 2004, 2007; Kuusk et al., 2008). It has been shown that predation on aphids early in the season can significantly decrease cereal aphid densities and delay their exponential increase (Edwards et al., 1979; Chiverton, 1987). High early-season rates of predation on aphids in the current study, therefore, may have provided a significant contribution to aphid control. However, besides feeding on aphids, $7.5 \%$ of the predators collected at the end of May had also consumed aphid parasitoids. This potentially weakens aphid control by parasitoids during their establishment phase, and more work is needed on the temporal affects of IGP on aphid control in future. Without molecular methods, these important early season interactions between generalist predators, aphids and their parasitoids would have been overlooked.

Although aphid densities increased significantly over time, the frequency of aphid DNA detection was not correlated with aphid availability in most predator groups. Similarly, detection rates of parasitoid prey were not correlated with the percentage of parasitized aphids available. Thus, factors other than the abundance of aphids might also have driven predation rates on aphids and parasitoids by generalist predators. For example, recent work has shown that the availability of alternative prey affects the level of predation on aphids by spiders and carabid beetles (Harwood et al., 2004; von Berg et al., 2009; Kuusk \& Ekbom, 2010), a phenomenon which might have affected predation on parasitoids as well. The densities of the predators changed significantly between the four sampling dates (fig. 1), being 1.5 to 3 times higher in July than on all earlier dates. Taking this numerical response into account, the actual predation rate (number of prey taken per predator) for both aphid and parasitoid prey probably increased significantly towards the aphids' population maximum, although relative aphid and parasitoid DNA detection 
rates were largely unaffected by sampling date. Note, however, that the increase in predator densities was largely affected by T. quadristriatus, a species which was found to prey less voraciously on aphids but which showed considerable detection frequencies of parasitoid DNA. Less abundant predators, such as N. biguttatus, staphylinids and other beetles, that showed high rates of aphid consumption throughout the aphid season, are likely to deliver a similar or even higher biocontrol service than the more abundant spiders and T. quadristriatus.

Predation rates by different taxa, measured using PCR, should always be compared with caution, as prey DNA detection success can vary significantly between different species (Greenstone et al., 2007; King et al., 2008). To adjust for inter-specific variation in DNA detection rates, data from feeding experiments can be used (Szendrei et al., 2010). However, adjusting field-derived molecular gut content data by feeding experiments is only feasible when assessing limited numbers of predator-prey links (e.g. Szendrei et al., 2010) and would require an impractically large amount of work to adjust feeding networks such as the current one. Thus, to allow for a more realistic comparison of prey found in predatory beetles and spiders in the present study, we down-weighted prey detection rates of spiders (mostly linyphiids), as previous studies have shown that post-feeding prey detection success is significantly higher in spiders than in beetles (e.g. Sheppard et al., 2005; Traugott \& Symondson, 2008). This adjustment showed that the role of spiders as predators of both aphids and parasitoids is comparable to that of the mainly small- and medium-sized beetle predators. Other unmeasured or unmeasurable parameters, such as feeding frequency and prey developmental stage, can affect prey DNA detection success too (e.g. all developmental stages may be present in the field simultaneously) (Traugott \& Symondson, 2008). Hence, although temporal changes within a particular trophic link can be analyzed easily, it is generally more difficult to compare prey detection rates between different taxa. The current data provide, nevertheless, new insights into the occurrence and frequency of direct and 'hidden' (parasitized prey) feeding interactions within an aphid-parasitoid-generalist predator community under natural conditions, with major implications for future work.

\section{Acknowledgements}

This study was funded by a Marie Curie Intra European Fellowship (no. 515216 P-P INTERACTIONS) granted to MT and held at Cardiff University with WOCS and a BBSRC grant no. 72/D19632 entitled 'Utilizing ecological profiling to evaluate the significance of predator biodiversity for sustainable pest regulation' held by WOCS at Cardiff University jointly with David Skirvin at HRI-Wellesbourne. We thank Lidija Kravar-Garde, Kelly Reynolds, Samuel Sheppard and David Skirvin for help during field work. We are also grateful to Corinna Wallinger and two anonymous referees for their suggestions which improved this paper and to Gilg Seeber for statistical advice.

\section{Supplementary material}

The online appendix and tables can be viewed at http:// journals.combridge.org/ber.

\section{References}

Agustí, N., Shayler, S.P., Harwood, J.D., Vaughan, I.P., Sunderland, K.D. \& Symondson, W.O.C. (2003) Collembola as alternative prey sustaining spiders in arable ecosystems: prey detection within predators using molecular markers. Molecular Ecology 12, 3467-3475.

Bell, J.R., Traugott, M., Sunderland, K.D., Skirvin, D.J., Mead, A., Kravar-Garde, L., Reynolds, K., Fenlon, J. \& Symondson, W.O.C. (2008a) Beneficial links for the control of aphids: the effects of compost applications on predators and prey. Journal of Applied Ecology 45, 1266-1273.

Bell, J.R., Mead, A., Skirvin, D.J., Sunderland, K.D., Fenlon, J. \& Symondson, W.O.C. (2008b) Do functional traits improve prediction of predation rates for a disparate group of aphid predators? Bulletin of Entomological Research 98, 587-597.

Bell, J.R., King, R.A., Bohan, D.A. \& Symondson, W.O.C. (2010) Spatial co-occurrence networks predict the feeding histories of polyphagous arthropod predators at field scales. Ecography 33, 64-72.

Brodeur, J. \& Rosenheim, J.A. (2000) Intraguild interactions in aphid parasitoids. Entomologia Experimentalis et Applicata 97, 93-108.

Cardinale, B.J., Harvey, C.T., Gross, K. \& Ives, A.R. (2003) Biodiversity and biocontrol: emergent impacts of a multienemy assemblage on pest suppression and crop yield in an agroecosystem. Ecology Letters 6, 857-865.

Chacon, J.M. \& Heimpel, G.E. (2010) Density-dependent intraguild predation of an aphid parasitoid. Oecologia 164, 213-220.

Chambers, R.J., Sunderland, K.D., Stacey, D.L. \& Wyatt, I.J. (1986) Control of cereal aphids by natural enemies - aphidspecific predators, parasitoids and pathogenic fungi. Annals of Applied Biology 108, 219-231.

Chiverton, P.A. (1987) Predation of Rhopalosiphum padi (Homoptera: Aphididae) by polyphagous predatory arthropods during the aphids' pre-peak period in spring barley. Annals of Applied Biology 109, 49-60.

Edwards, C.A., Sunderland, K.D. \& George, K.S. (1979) Studies on polyphagous predators of cereal aphids. Journal of Applied Ecology 16, 811-823.

Eitzinger, B. \& Traugott, M. (2011) Which prey sustains coldadapted invertebrate generalist predators in arable land? Examining prey choices by molecular gut content analysis. Journal of Applied Ecology 48, 591-599.

Greenstone, M.H., Rowley, D.L., Weber, D.C., Payton, M.E. \& Hawthorne, D.J. (2007) Feeding mode and prey detectability half-lives in molecular gut-content analysis: an example with two predators of the Colorado potato beetle. Bulletin of Entomological Research 97, 201-209.

Harwood, J.D., Sunderland, K.D. \& Symondson, W.O.C. (2004) Prey selection by linyphiid spiders: molecular tracking of the effects of alternative prey on rates of aphid consumption in the field. Molecular Ecology 13, 3549-3560.

Harwood, J.D., Desneux, N., Yoo, H.J.S., Rowley, D.L., Greenstone, M.H., Obrycki, J.J. \& O'Neil, R.J. (2007) Tracking the role of alternative prey in soybean aphid predation by Orius insidiosus: a molecular approach. Molecular Ecology 16, 4390-4400.

Hesterberg, T., Moore, D.S., Monaghan, S., Clipson, A. \& Epstein, R. (2003) Bootstrap methods and permutation tests. pp. 14.1-14.70 in Moore, D.S. \& McCabe, G.P. (Eds) Introduction to the Practice of Statistics. New York, USA, W H Freeman \& Co. 
Juen, A. \& Traugott, M. (2007) Revealing species-specific trophic links in soil food webs: Molecular identification of scarab predators. Molecular Ecology 16, 1545-1557.

King, R.A., Read, D.S., Traugott, M. \& Symondson, W.O.C. (2008) Molecular analysis of predation: a review of best practice for DNA-based approaches. Molecular Ecology 17, 947-963.

King, R.A., Vaughan, I.P., Bell, J.R., Bohan, D.A. \& Symondson, W.O.C. (2010) Prey choice by carabid beetles feeding on an earthworm community analysed using species- and lineage-specific PCR primers. Molecular Ecology 19, 1721-1732.

Kuusk, A.-K. \& Ekbom, B. (2010) Lycosid spiders and alternative food: feeding behavior and implications for biological control. Biological Control 55, 20-26.

Kuusk, A.-K., Cassel-Lundhagen, A., Kvarnheden, A. \& Ekbom, B. (2008) Tracking aphid predation by lycosid spiders in spring-sown cereals using PCR-based gutcontent analysis. Basic and Applied Ecology 9, 718-725.

Macfadyen, S., Gibson, R., Polaszek, A., Morris, R.J., Craze, P.G., Planque, R., Symondson, W.O.C. \& Memmott, J. (2009) Do differences in food web structure between organic and conventional farms affect the ecosystem service of pest control? Ecology Letters 12, 229-238.

Müller, C.B., Adriaanse, I.C.T., Belshaw, R. \& Godfray, H.C.J. (1999) The structure of an aphid-parasitoid community. Journal of Animal Ecology 68, 346-370.

Nakamura, M. \& Nakamura, K. (1977) Population dynamics of the chestnut gall wasp, Dryocosmus kuriphilus Yasumatsu (Hymenoptera: Cynipidae). V. Estimation of the effect of predation by spiders on the mortality of imaginal wasps based on the precipitin test. Oecologia 27, 97-116.

Östman, Ö., Ekbom, B. \& Bengtsson, J. (2003) Yield increase attributable to aphid predation by ground-living polyphagous natural enemies in spring barley in Sweden. Ecological Economics 45, 149-158.

Polis, G.A., Myers, C.A. \& Holt, R.D. (1989) The ecology an evolution of intraguild predation: potential competitors that eat each other. Annual Review of Ecology and Systematics 20, 297-330.

Ruggle, P. \& Holst, N. (1994) Life history parameters of parasitoids attacking cereal aphids. Norwegian Journal of Agricultural Sciences 16, 83-88.

Schmidt, M.H., Lauer, A., Purtauf, T., Thies, C., Schaefer, M. \& Tscharntke, T. (2003) Relative importance of predators and parasitoids for cereal aphid control. Proceedings of the Royal Society of London, Series B: Biological Sciences 270, 1905-1909.

Schmidt, M.H., Thewes, U., Thies, C. \& Tscharntke, T. (2004) Aphid suppression by natural enemies in mulched Cereals. Entomologia Experimentalis et Applicata 113, 87-93.

Sheppard, S.K., Bell, J.R., Sunderland, K.D., Fenlon, J., Skervin, D. \& Symondson, W.O.C. (2005) Detection of secondary predation by PCR analyses of the gut contents of invertebrate generalist predators. Molecular Ecology 14, 4461-4468.

Sint, D., Raso, L., Kaufmann, R. \& Traugott, M. (2011) Optimizing methods for PCR-based analysis of predation. Molecular Ecology Resources 11, 795-801.

Snyder, G.B., Finke, D.L. \& Snyder, W.E. (2008) Predator biodiversity strengthens aphid suppression across singleand multiple-species prey communities. Biological Control 44, $52-60$.

Snyder, W.E. \& Ives, A.R. (2001) Generalist predators disrupt biological control by a specialist parasitoid. Ecology 82, 705-716.

Sunderland, K.D., Axelsen, J.A., Dromph, K., Freier, B., Hemptinne, J.-L., Holst, N.H., Mols, P.J.M., Petersen, M. K., Powell, W., Ruggle, P., Triltsch, H. \& Winder, L. (1997) Pest control by a community of natural enemies. Acta Jutlandica 72, 271-326.

Symondson, W.O.C. (2002) Molecular identification of prey in predator diets. Molecular Ecology 11, 627-641.

Szendrei, Z., Greenstone, M.H., Payton, M.E. \& Weber, D.C. (2010) Molecular gut-content analysis of a predator assemblage reveals the effect of habitat manipulation on biological control in the field. Basic and Applied Ecology 11, 153-161.

Traugott, M. \& Symondson, W.O.C. (2008) Molecular analysis of predation on parasitized hosts. Bulletin of Entomological Research 98, 223-231.

Traugott, M., Bell, J.R., Broad, G.R., Powell, W., van Veen, F.J.F., Vollhardt, I.M.G. \& Symondson, W.O.C. (2008) Endoparasitism in cereal aphids: molecular analysis of a whole parasitoid community. Molecular Ecology 17, 3928-3938.

van Emden, H.F. \& Harrington, R. (2007) Aphids as Crop Pests. Wallingford, UK, CABI.

van Veen, F.J.F., Morris, R.J. \& Godfray, H.C.J. (2006) Apparent competition, quantitative food webs, and the structure of phytophagous insect communities. Annual Review of Entomology 51, 187-208.

van Veen, F.J.F., Müller, C.B., Pell, J.K. \& Godfray, H.C.J. (2008) Food web structure of three guilds of natural enemies: predators, parasitoids and pathogens of aphids. Journal of Animal Ecology 77, 191-200.

Vance-Chalcraft, H.D., Rosenheim, J.A., Vonesh, J.R., Osenberg, C.W. \& Sih, A. (2007) The influence of intraguild predation on prey suppression and prey release: a meta-analysis. Ecology 88, 2689-2696.

Völkl, W. \& Kraus, W. (1996) Foraging behaviour and resource utilization of the aphid parasitoid Pauesia unilachni: adaptation to host distribution and mortality risks. Entomologia Experimentalis et Applicata 79, 101-109.

von Berg, K., Thies, C., Tscharntke, T. \& Scheu, S. (2009) Cereal aphid control by generalist predators in presence of belowground alternative prey: Complementary predation as affected by prey density. Pedobiologia 53, 41-48. 